LBL- -32791

DE93 001591

\title{
Ripple Reduction Activities in the MG Room at the Bevatron August 1991 to August 1992
}

\author{
M. Blasbalg and M. Bennett \\ Accelerator and Fusion Research Division \\ Lawrence Berkeley Laboratory \\ University of California \\ Berkeley, California 94720
}

August 1992

This work was supported by the Director, Office of Energy Research, Office of High Energy and Nuclear Physics, High Energy Physics Division, of the U.S. Department of Energy under Contract No. DE-AC0376SF00098. 


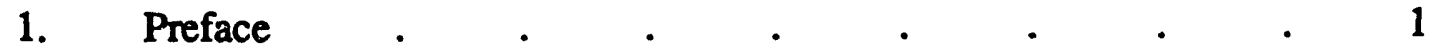

2. Magnet - Voltage Dividers Temperature \& Voltage Influence . 2-3 Error calculation (p. 75 in Logbook)

3. Magnet Filters Summarized Data Table (p. 91 in Logbook). . 4 - 5

4. Magnet Transfer Function Measurement Setup and Connection . $6-10$ Diagrams (p. 121 in Logbook)

5. Response of Existing Magnet System Including Ripple Reduction . Filters - Dec 1991 (p. 122 in Logbook)

6. Magnet Filters - Mutual Inductance Problem (p. 130 in Logbook) .

7. Damping The Magnet Filters (p. 137 in Logbook) . . . $14-20$

-- Spice Simulations

-- Real System "Cold" Response

-- Real System "Hot" Response

-- Real System Spill Histograms for a Damped and Undamped Magnet Filter System.

8. Conclusions and Recommendations for the Future. . . . 21 


\section{IMPROVEMENTS OF THE BEVATRON SYSTEM}

\section{Preface}

This job was supervised by C. Celata and is a continuation of R. Salomons and C. Celata's work in the year 1990-1991.

The major task was to improve the spill to a more continuous flow out of particles during the spillout of the particles from the Bevatron Accelerator. The work concentrated on reduction of the ripple and "softening" over the transfer function of the ripple control system. Detailed information and data can be found in the R. Salomons / M. Blasbalg logbook and on the hard disc storage system of the TEK 2630 Fourier Analyzer according to file numbers that are mentioned in the logbook.

2. Magnet Voltage Dividers ( Page 80 in logbook)

Since the cross magnet ac voltages and responses are taken across the dividers which are connected at the magnet corners, these dividers had to be examined very carefully with respect to their temperature and voltage behavior.

According to the MFG company of the resistor, the stability should be in the range

of: $\quad \mathrm{TCR}=-550 \mathrm{PPM} /{ }^{\circ} \mathrm{C}$

$$
\mathrm{VCR}=-25 \mathrm{PPM} / \mathrm{VOLT}
$$

Both these figures were tested and the resistor behaved within these limited ranges. 
The error for cross magnet measurement was calculated according to MFG's stability and accuracy data.

The error (theoretically calculated) was $\approx 1 \%$.

$$
\frac{\Delta(\mathrm{V} 2-\mathrm{V} 1)}{(\mathrm{V} 2-\mathrm{V} 1)}=1 \%
$$

This error is negligible.

\section{Magnet Filters (Page 91 in Logbook) - Summarized Data Table}

The Table includes the data for the $175,355,680,1080,1355 \mathrm{~Hz}$ filters on the \pm 1 and \pm 2 magnets.

$\mathrm{L} \quad$ Filter inductance in mHy (measured)

$\mathrm{L}_{\mathbf{n}} \quad$ Filter inductance in mHy calculated according to the mid band filter frequency and measured capacitors which are connected in parallel

C Total capacitance in $\mu \mathrm{F}$ (measured)

$R \quad$ Total resistance between filter buss terminals in $\mathrm{m}$ ohms (measured)

foFc Calculated filter band center frequency according to measured actual filters 
foFn Calculated required filter band center frequency, according to lowest and highest slip factors

fmax Maximum expected frequency (Lowest Field)

fmin Minimum expected frequency (Highest Field)

BWc Filter bandwidth - Calculated

$$
\begin{aligned}
& B W= \frac{f o}{Q} Q=\frac{\text { WoL }}{R} \\
& B W n \text { Real required BW }
\end{aligned}
$$

NOTE:Slip factors were calculated as follows:

$$
\mathrm{K} \max =\frac{890}{900} \quad \mathrm{Kmin}=\frac{869}{900}
$$


TABLE

FILTERS Values of R, C. L, Calcu

\begin{tabular}{|c|c|c|c|c|c|c|}
\hline & $175(180)$ & $355(360)$ & $680(720)$ & $1018(1080)$ & $1355(1440)$ & $60 \mathrm{~Hz}$ \\
\hline & 105 Trns & & & & & \\
\hline$L(m H y)$ & 10.26 & 0.868 & 0.864 & 1.458 & 0.926 & \\
\hline $\operatorname{Ln}(\mathrm{mH} H)$ & 10.24 & 1.017 & 0.8231 & 1.39 & 0.8873 & 25.13 \\
\hline$C(\mu F)$ & 81.8 & 206 & 63.6 & 16.74 & 14.75 & 300 \\
\hline$R(m \Omega)$ & 140.71 & 16.68 & 48.25 & 53.72 & 48.36 & 345.3 \\
\hline FOFC & 173.728 & 376 & 678.945 & 1018.741 & 1361.817 & \\
\hline FOFN & 173.9 & 347.8 & 695.6 & 1043.4 & 1391.2 & 57.97 \\
\hline$f \max$ & 178 & 356 & 712 & 1068 & 1424 & 59.3 \\
\hline$f \max c(-3 d b)$ & 174.82 & 377.53 & 683.385 & 1021.674 & 1365.976 & \\
\hline$f \min c(-3 d b)$ & 172.637 & 374.47 & 674.505 & 1015.809 & 1357.66 & \\
\hline$f \min$ & 169.8 & 339.6 & 679.2 & 1018.8 & 1358.4 & 56.6 \\
\hline$B W_{C}$ & 2.183 & 3.057 & 8.88 & 5.865 & 8.314 & \\
\hline $\bar{Q}$ & 79.6 & 123 & 76.4 & 173.7 & 163.8 & \\
\hline$B W n$ & 8.2 & 16.4 & 32.8 & 49.2 & 65.6 & \\
\hline fo(m) & 170.5 & 342 & 624.2 & 965.7 & 1290 & \\
\hline ATT@(m) & -34.7 & -52.1 & -36.5 & $-18: 37$ & -24.2 & \\
\hline ATT(m)@fmax & -21.5 & -37.5 & -24.5 & -14.8 & -18.1 & \\
\hline ATT(m)@fmin & -33 & -36.2 & -28 & -16 & 21.1 & \\
\hline & $175(180)$ & $355(360)$ & $680(720)$ & $1018(1080)$ & $1355(1660)$ & $120 \mathrm{~Hz}$ \\
\hline & 103.3 Trans & & & & & \\
\hline$L(m H y)$ & 10.1 & 0.872 & 0.842 & 1.375 & 0.905 & \\
\hline $\operatorname{Ln}(\mathrm{mHy})$ & & & & & & 12.57 \\
\hline$C(\mu \mathrm{F})$ & 82.8 & 204 & 63 & 16.88 & 14.86 & 150 \\
\hline$R(m \Omega)$ & 137 & 15.85 & 48.06 & 51.86 & 44.87 & 172.7 \\
\hline FOFC & 174.038 & 377.352 & 691.025 & 1044.678 & 1372.418 & 115.9 \\
\hline & & & & & & \\
\hline fOFN & 173.9 & 347.8 & 695.6 & 1043.4 & 1391.2 & 115.9 \\
\hline & & & & & & \\
\hline $\mathrm{fmax}$ & 178 & 356 & 712 & 1068 & 1424 & 118.7 \\
\hline$f \max c(-3 d b)$ & 175.123 & 378.8 & 695.567 & 1047.68 & 1376.364 & \\
\hline$f \min c(-3 d b)$ & 172.953 & 375.905 & 686.483 & 1041.676 & 1368.472 & \\
\hline$f \min$ & 169.8 & 339.6 & 679.2 & 1018.8 & 1358.4 & 113.2 \\
\hline$B W C$ & 2.17 & 2.894 & 9.084 & 6.004 & 7.892 & \\
\hline$Q$ & 80.2 & 130.4 & 76.07 & 174 & 173.9 & \\
\hline$B W n$ & 8.2 & 16.4 & 32.8 & 49.2 & 65.6 & \\
\hline fo $(m)$ & & & & & & \\
\hline ATT@(m) & & & & & & \\
\hline ATT(m)@ima & & & & & & \\
\hline ATT(m)@fmin & & & & & & \\
\hline
\end{tabular}


TABLE

FILTERS Values of $R, C, L$, Calcu

$B W n=f \operatorname{mx}-\mathrm{fmin} ; \max +K_{\max }$ fon; $f \min =\mathrm{Kmin} \cdot \mathrm{fon} ; \mathrm{Kmax}=\frac{890}{900} ; \mathrm{Kmin}=\frac{849}{900}$
foFn nominal filter center frequency to be: $\frac{\mathrm{fmax}=\mathrm{fmin}}{(2)}$

LN calculated nom. filter coil inductance

foFC calculated filter center frequency

fmax maximum possible frequency at the filter band $=f$ nominal $\cdot K m a x$

fmin minimum possible frequency at the filter band $=f$ nominal $\cdot \mathrm{Kmin}$

$B W c=\frac{f_{0}}{Q} \quad 3 d B$ bandwidth of the filter calculated

fminc $(-3 d B)$ lower $-3 A B$ calculated frequency

fmaxc $(-3 d B)$ higher-3db calculated frequency

fFm measured filter center frequency

$\mathrm{BWn}$ real necessary $\mathrm{BW}=\mathrm{fmax}-\mathrm{fmin}$ 


\section{Magnet Transfer Function Measurement Setup and Connection Diagrams}

(Page 91 in Logbook)

The setup on DWG 4-1 to 4-4 is designed to measure the cross magnet response in the real system with and without filters. Two amplifiers (var gain $G_{v} 28 \div 75$ ) were designed - antiphased, (OP AMP1 $\left.\mathrm{CH} 1, \mathrm{CH}_{2}\right)$ and two others were designed $(\mathrm{GV}=28)$ which are in phase. (OP AMP2 $\mathrm{CH} 1, \mathrm{CH}_{2}$ ) in addition a different amp was added (OP $\mathrm{AMP}_{3}$.

The amps have a minimum response of $\mathrm{DC}$ to $2 \mathrm{KHZ}$. The different setups are as follows:

DWG \#4-1 Amplifiers calibration

DWG \#4-2 System setup calibration

DWG \#4-3 Measuring the filters without magnet

DWG \#4-4 Measuring the magnet and the filters.

S1 shorted is used for system calibration. This measuring system is connected to the Fourier Analyzer TEK-2630 as the following: the sweep signal connected to OP AMP 1 $\mathrm{CH}_{1}, \mathrm{CH}_{2}$.

CH1 Monitoring the input sweep signal

$\mathrm{CH} 2$ Output of the measuring chain -- response function

CH3 Output of OPAMP1 CH1

$\mathrm{CH} 4$ Output of OPAMP2 CH1

On page 109 the calibration response is seen while the magnet is shorted. 
DWG 4-1

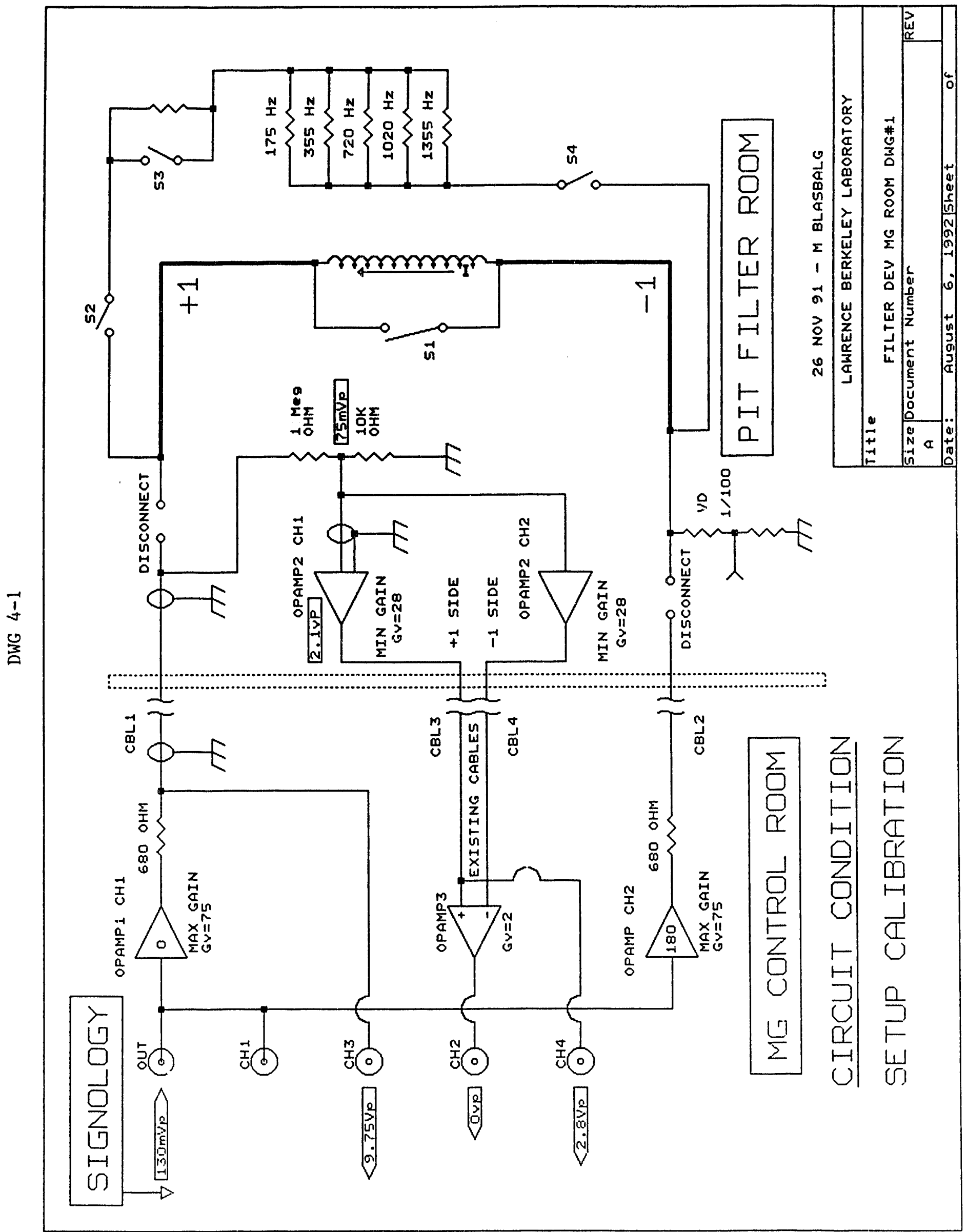




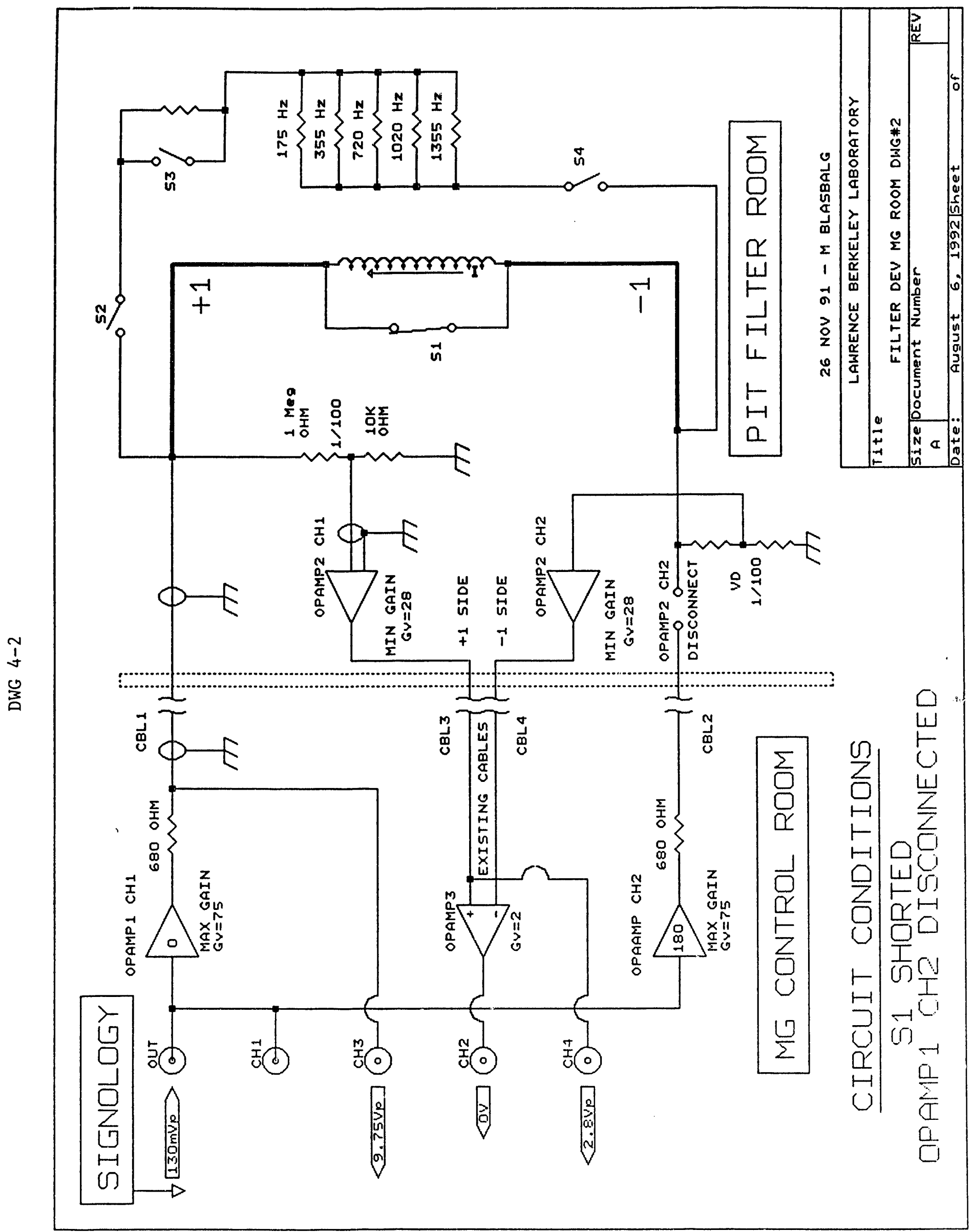


DWG 4-3

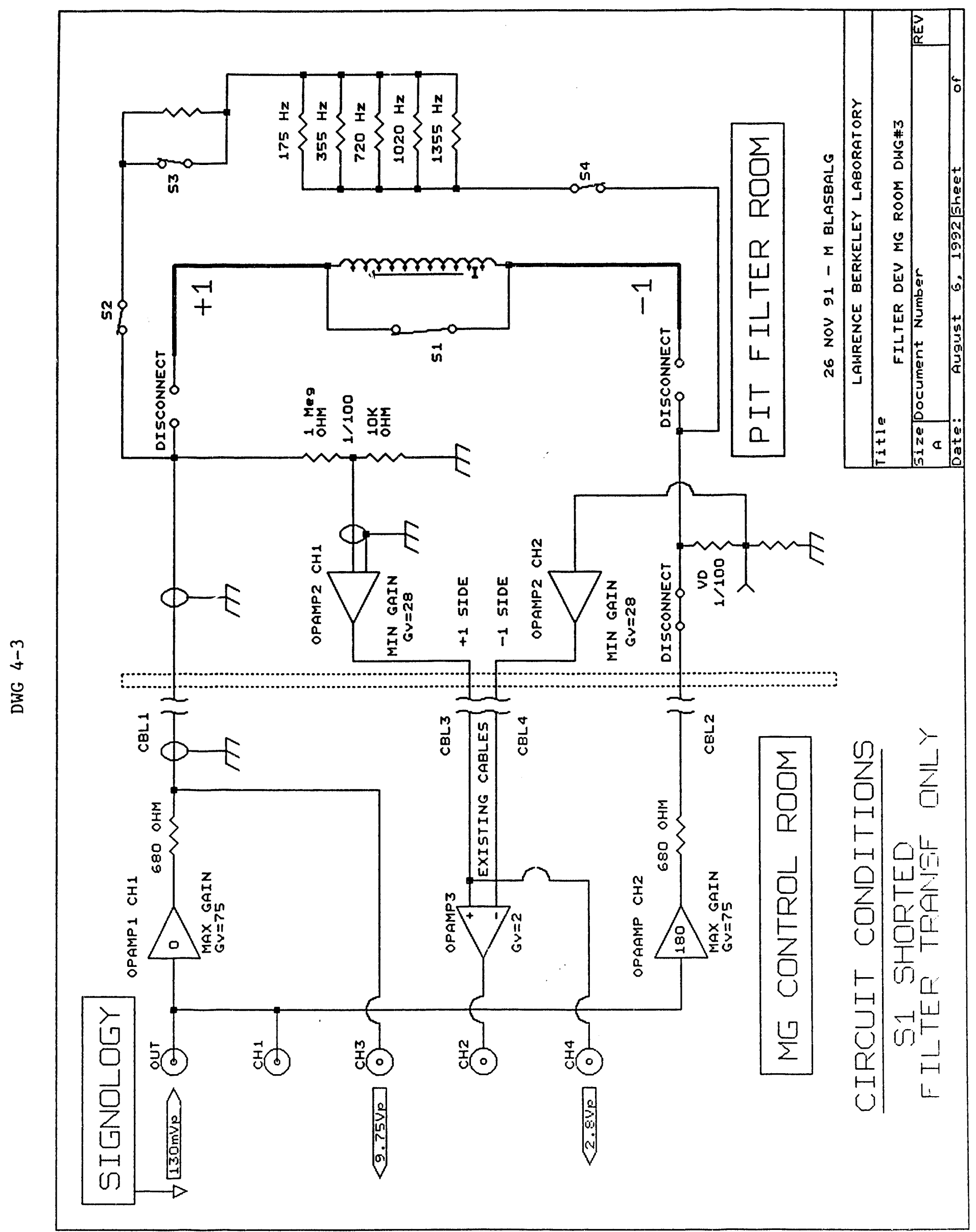




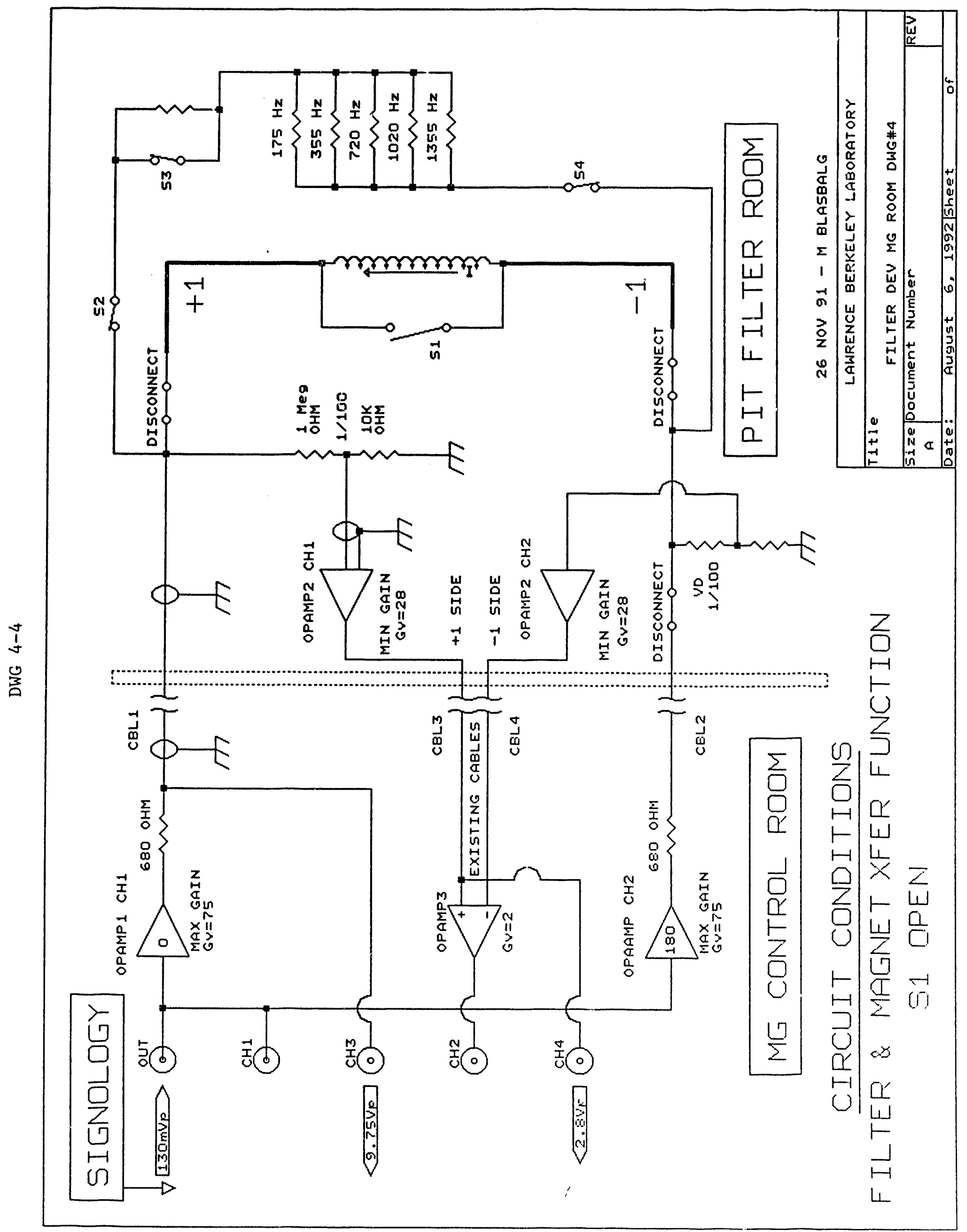


The programmed scales of the TEK 2630 were used to use and achieve the maximum available dynamic range.

5. Response of Existing Magnet System Including Ripple Reduction Filters (Page 122 in logbook)

The response of both magnets \pm 1 and \pm 2 are given on Page 122 to 125 in the logbook.

On Page 122 a (SPICE) simulation is given as well.

Except for frequency accuracy (shifted center frequency in existing filters due to inaccuracy of components), 3 major problems are seen:

a. A bump of the response function at around $5 \mathrm{~Hz}$

b. An interaction between the filters and magnet. This transient is seen also in the SPICE simulation.

c. We found that this sharpness degradation occurs due to mutual inductance/loading of the coils/filters. After repositioning of the filter coils down in the filter pit, this problem was solved. 
6. Magnet Filters - Mutual Inductance Problem (Page 130 in Logbook)

As mentioned in paragraph 4.(a) the response degradation was due to mutual inductance. This was proven by flipping the filter coil over, physically achieving a $180^{\circ}$ change in mutual inductance. The result of this experiment is in the Logbook, page 129, 130 , original position page.

On page 130 the "flipped over" coil configuration is shown for magnet \pm 2 . Various configurations in which coils are positioned vertically each to another are shown on pages 137 through 139. The response of (the new assembled filter pit) the magnet and filters is shown on page 194 in the Logbook. 

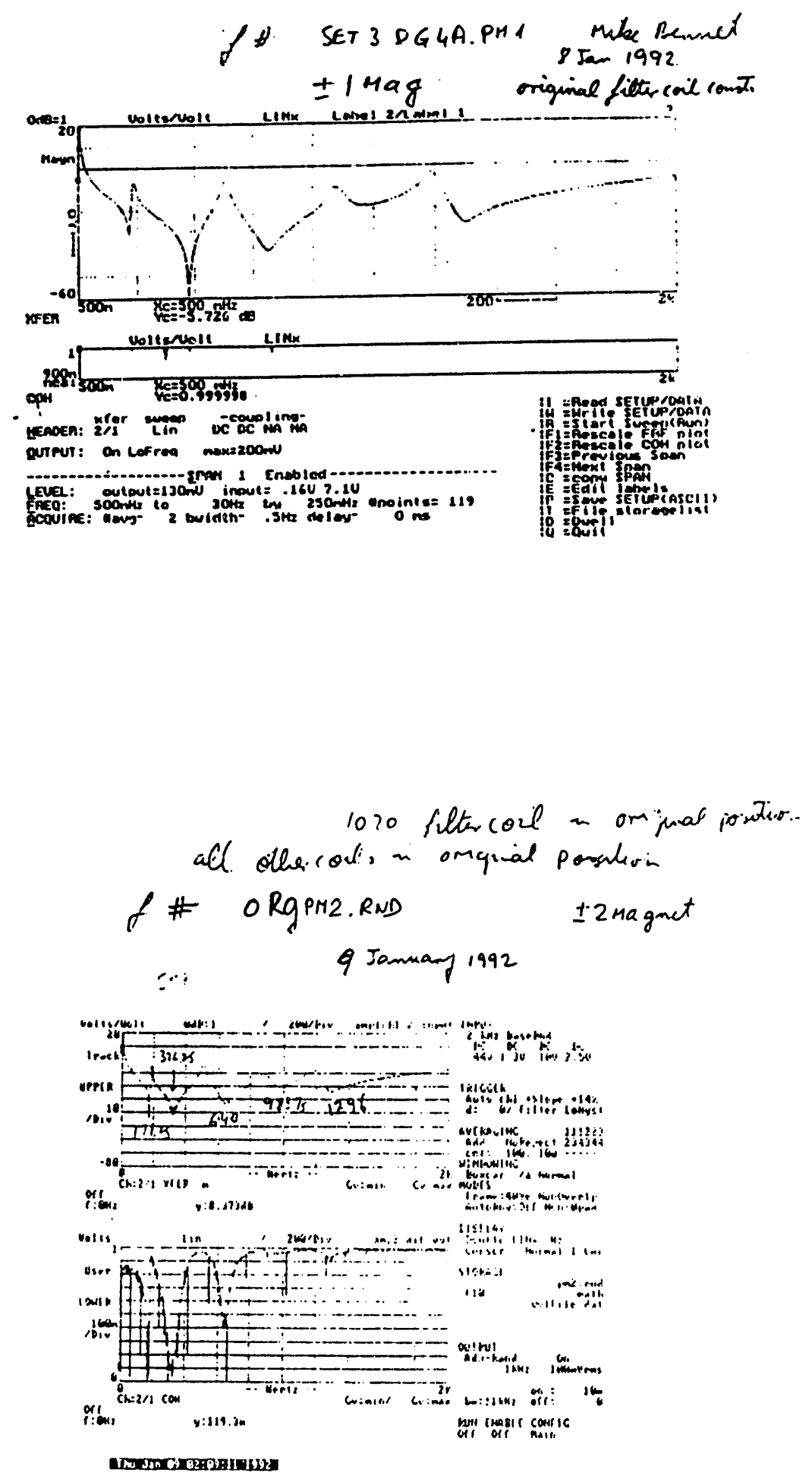

SPICE SIMULATIONS FOR DAMPED AND UNDAMPED FILTER SYSTEM 


\section{Damping the Magnet Filters (page 137 in Logbook)}

\subsection{Filters and spurious behavior across the magnet.}

Since the filters are series resonant circuits (in different frequencies) which are connected in parallel to the big magnet (each half magnet has an induction of $2.5 \mathrm{Hy}$ ), the response of the half magnet, including filters, will be a multi notch response. In our case, 5 notches in the $175_{\mathrm{Hz}} 355_{\mathrm{Hz}} 680 \mathrm{~Hz} 1080_{\mathrm{Hz}} 1355_{\mathrm{Hz}}$ frequencies. Spurious frequencies (generator harmonics) are damped in these frequencies according to the notch depth and shape.

Since the ripple reduction control system includes somewhere the filters (because our ripple source includes the magnet and filters) it is "healthy" for a control system not to have abrupt phase variations as a function of frequency. Our solution to this problem was to decrease the sharpness of the filter notches which resulted in smoother phase response in the notch regions. An additional advantage of damping the resonance circuits (filters) is that their influence in the frequency domain is broadened around the center/resonance frequency.

The disadvantage ("where we pay") is, that the notches are not deep as in the undamped configuration. SPICE simulations were done for various different damping configurations. Measured and simulation results are on pages 194, 195 in the logbook.

Damped filters were tested in a "hot machine". Spurious magnitudes were measured in the $0-2 \mathrm{KHZ}$ band on both halves of the magnets.

In low fields the damped configuration caused an increase of spuriouses at the lower band in an amount that was unacceptable. 
In medium and high fields an improvement along the whole band was recognized.

The values of the damping resistors in the different damping configurations, including spurious magnitudes in different fields, is given in tables on page 191, 192, in the logbook.

The next step was testing filters in a running "hot" machine while particles spill is extracted.

\subsection{Damped Magnet Filters 1st Configuration -- Spill Histograms.}

On pages 175 to 177 in the logbook are the results of a BevDev with damp'd filters where spill histograms were taken with damped and undamped filters.

If we compare the original configuration with ripple reduction on to the damped configuration with ripple reduction on, we can notice a clear improvement for the amount of $2 \cdot 10^{8}$ particles.

7.3 Damped Filters 2nd Set of Configurations 

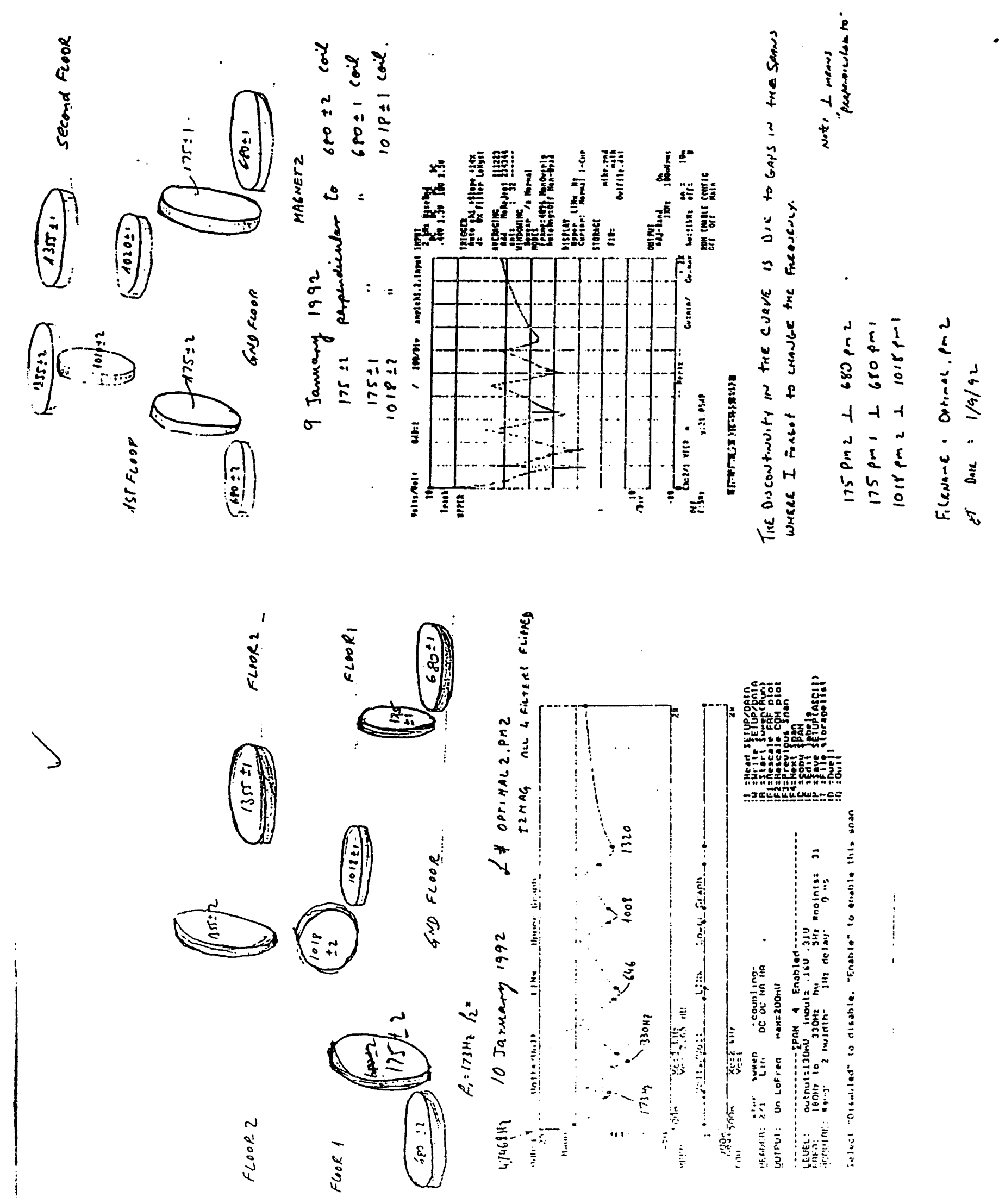

System Measuring Results With Original Filters and With Damped Filters

(Data was taken with TEK 2630) 

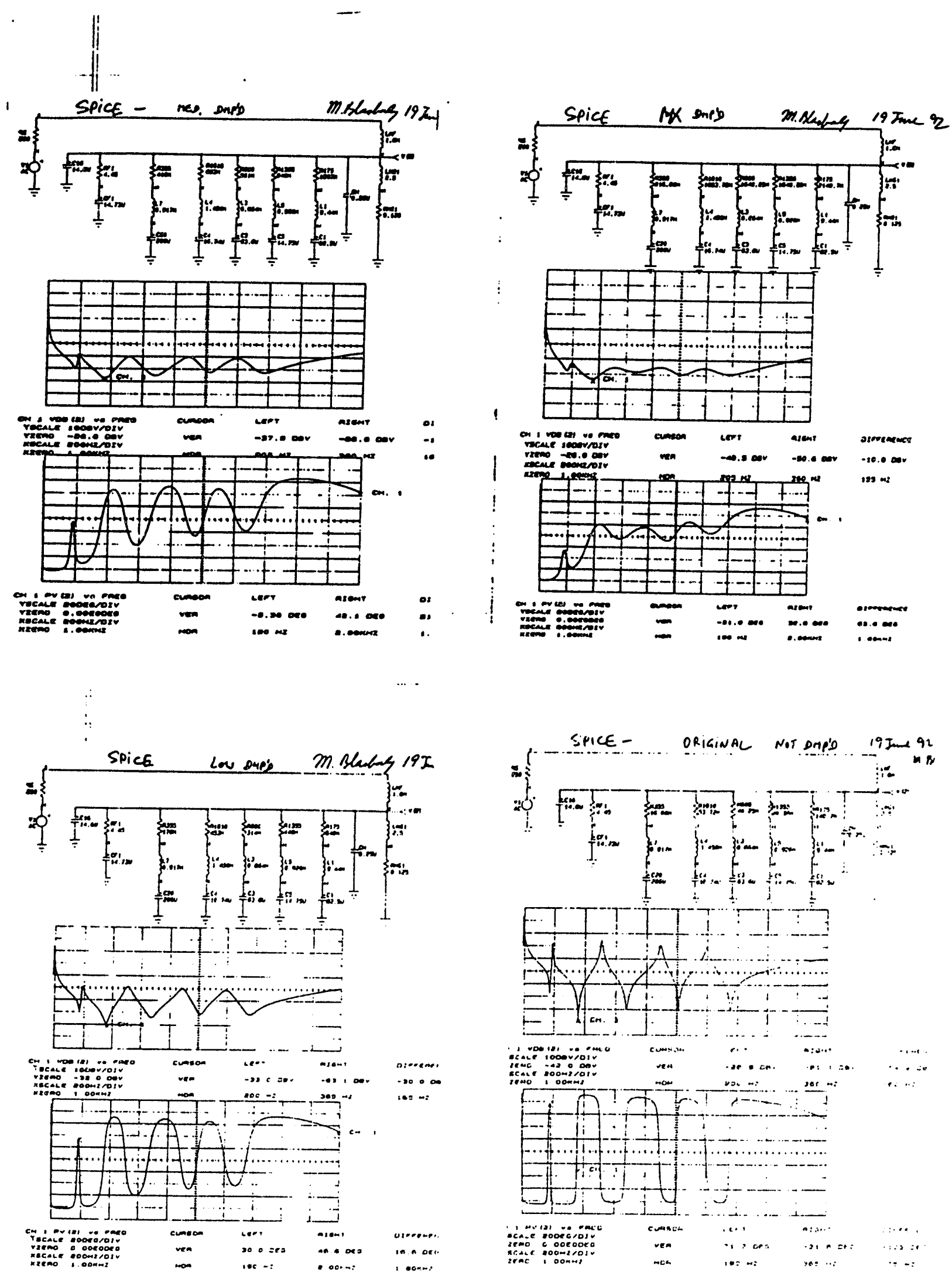

SPICE SIMULATIONS FOR DAMPED AND UNDAMPED FILTER SYSTEM 


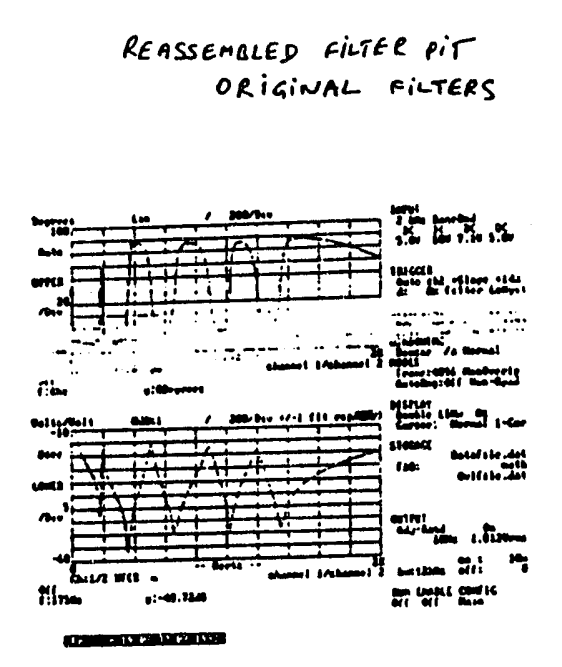

\pm 1 MAC

No dan-noms

m. Bemant

m. Bemat

$$
\begin{aligned}
& =1 \text { mate } \\
& \text { Meo binpirs } \\
& \text { M. Zanett }
\end{aligned}
$$

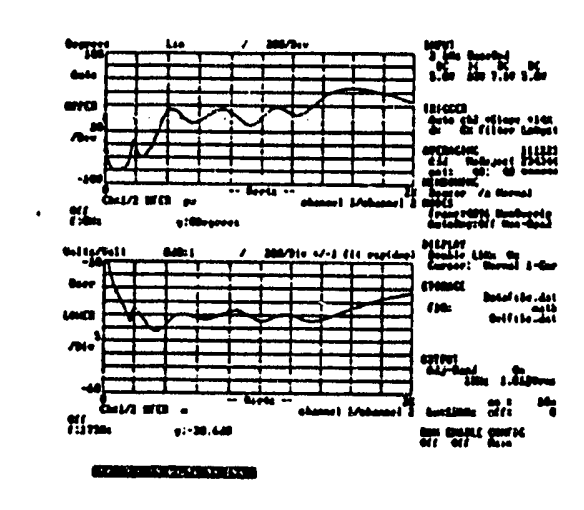

RTASSEMBLED FILTERPIT

MEDIUM DAMPD

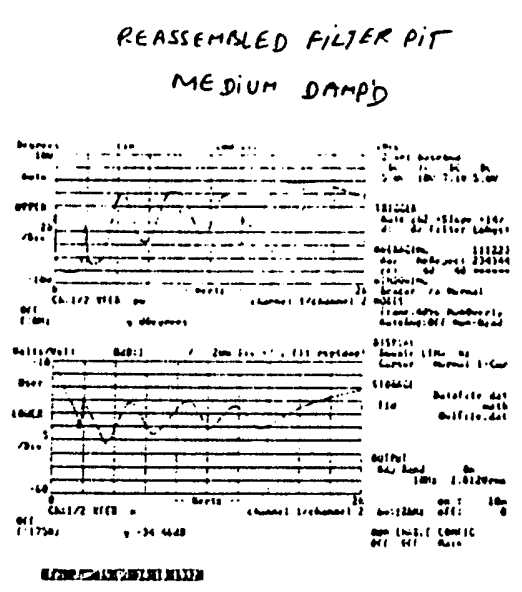

MAX DMP's

Minimum SAMPI

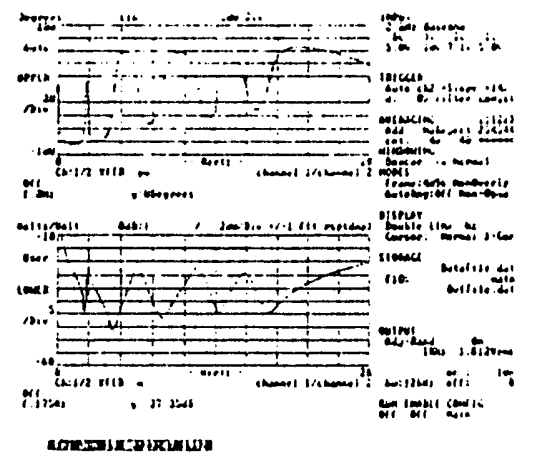

$\pm 1$

Mar danom

M Bent

SYSTEM MEASURING RESULTS WITH ORIGINAL FILTERS AND WITH DAMPED FILTERS. DATA IVAS TAKEN IWITH TEK 263() 
Another set of 3 damped filters configurations was prepared and SPICE simulated. The new damping resistor values were defined according to the experience with the first set of configurations. Refer to pages 194 to 198 in logbook. This set of configurations was not tested still in a hot machine and while spilling particles (histograms).
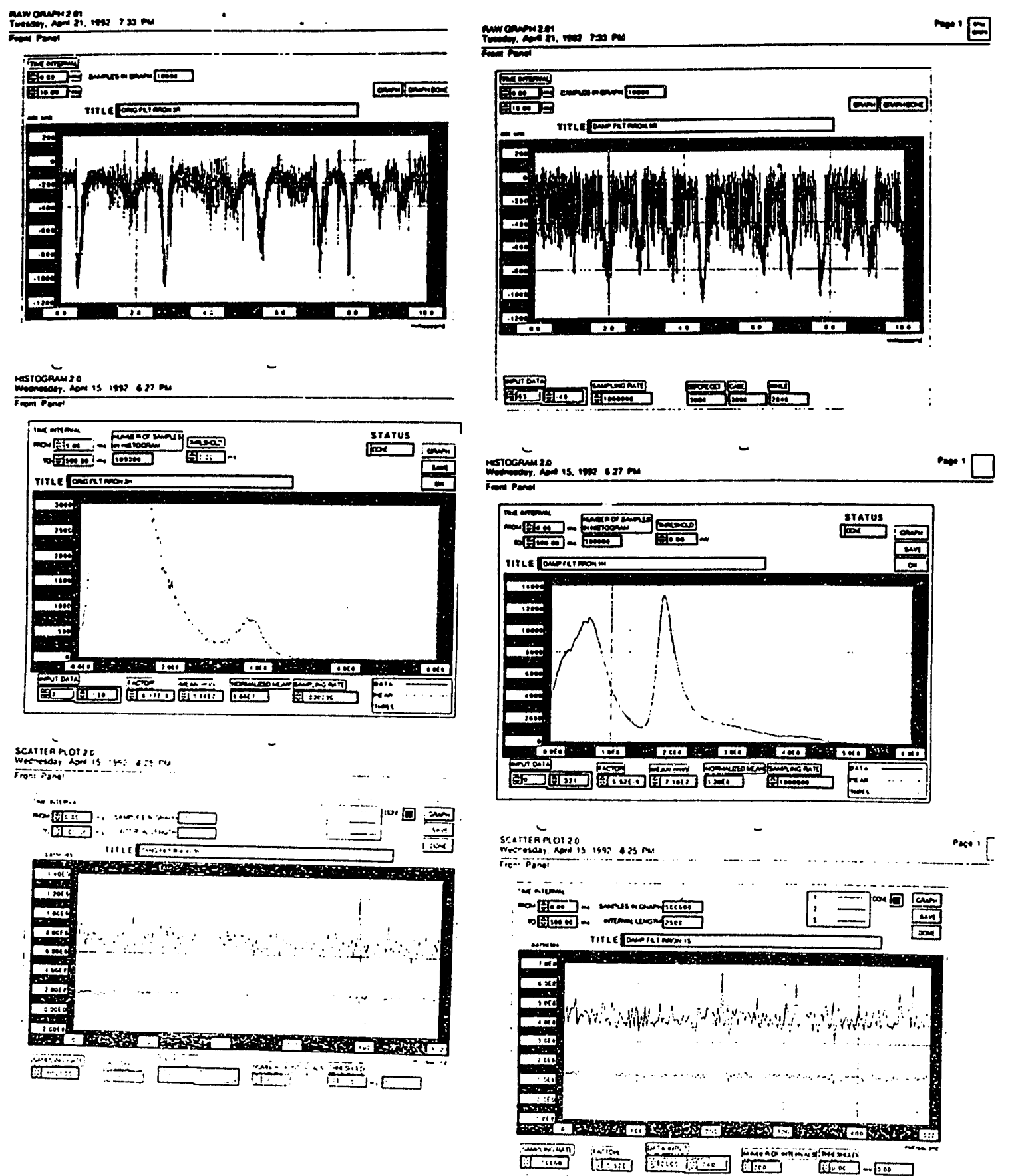

SPILL HISTOGRAMS IN AN ORIGINAL AND DAMPED SYSTEM 

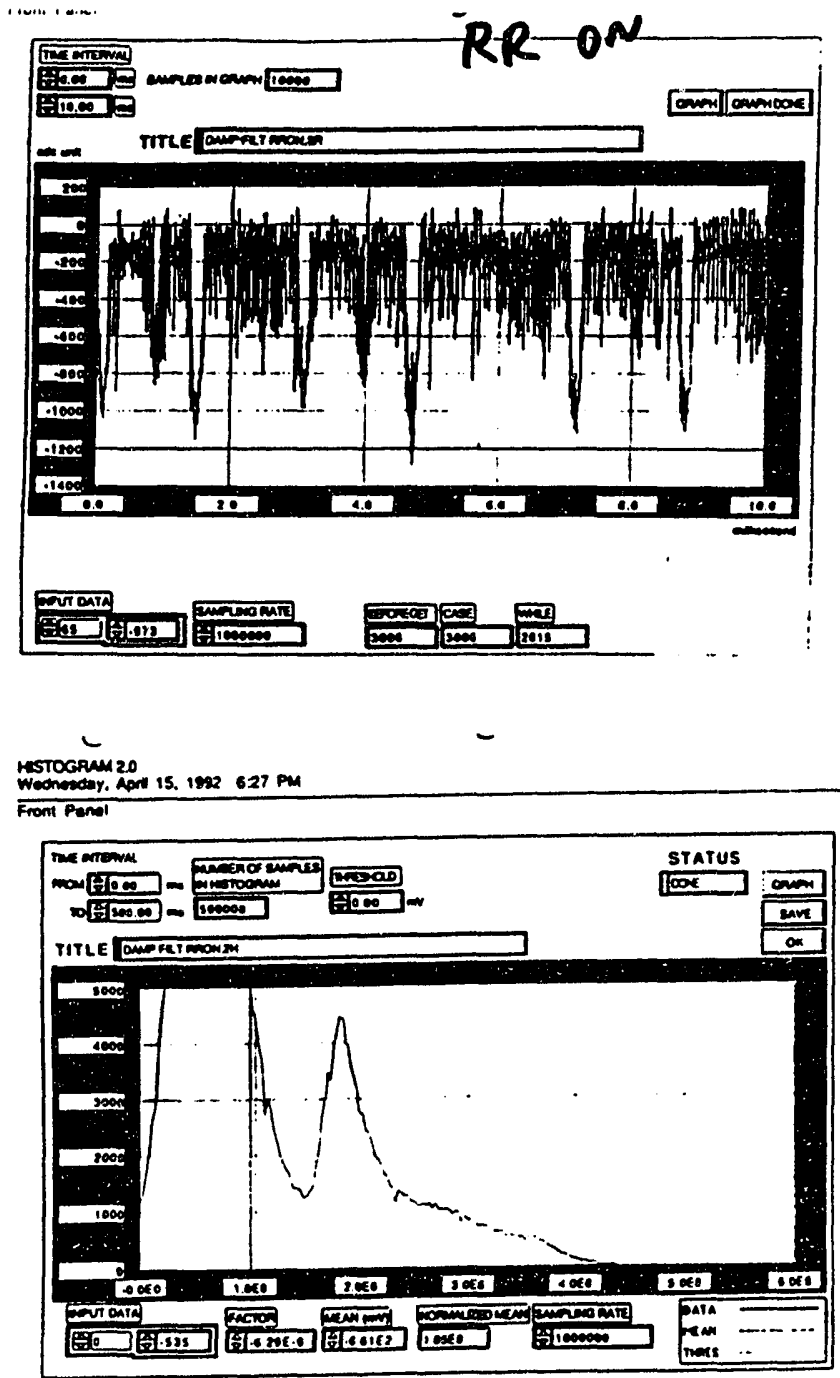

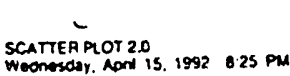

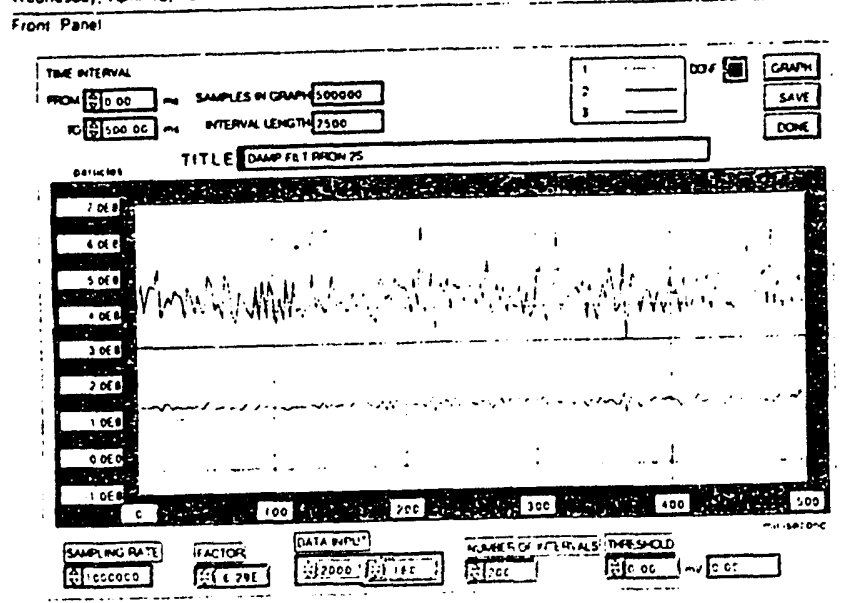

RAWGRAPN 2.01, Popt: From Panel

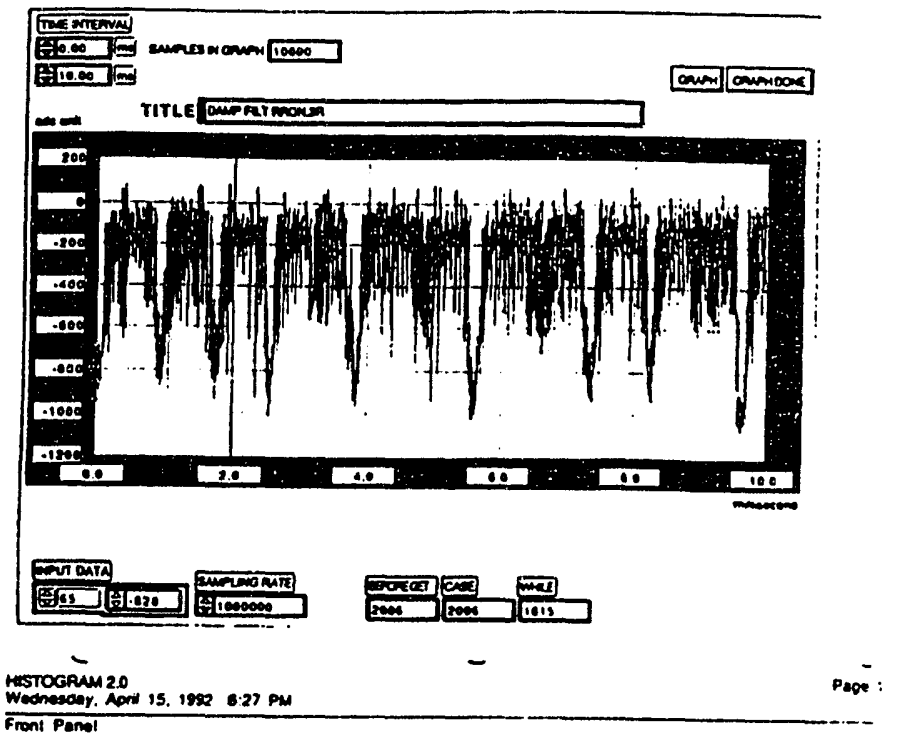
Front Penel

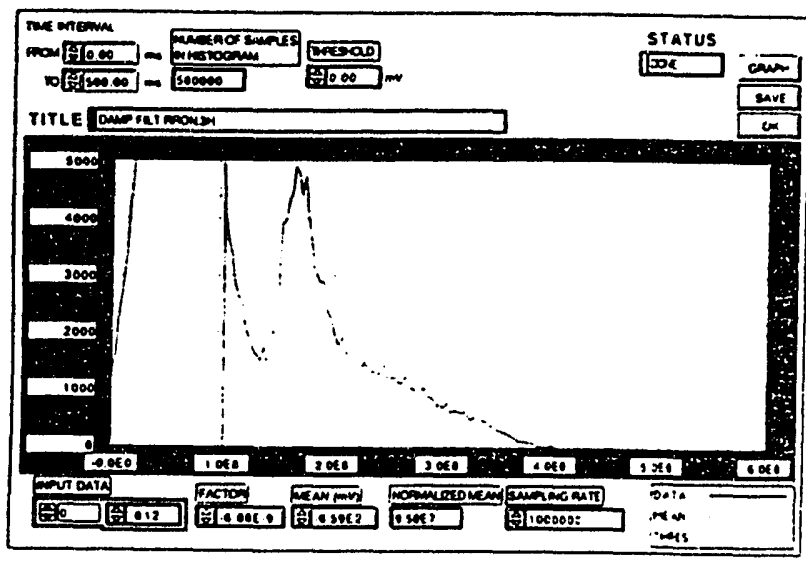

SCATIER PLOY 20 OS 1992 \& 25 PM Fiont Pane

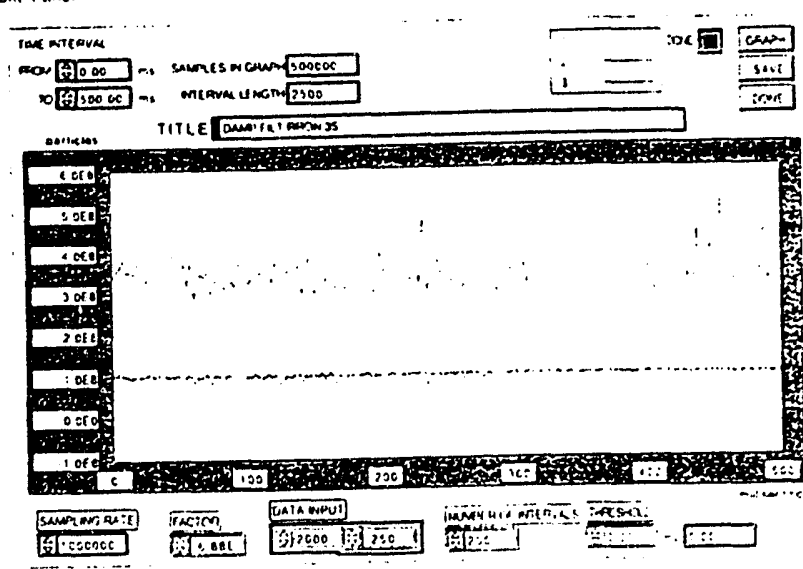

SPILL HISTOGRAMS IN A DAMPED FILTER SYSTEM 
8. Conclusions and Recommendations for the Future

\section{1 $5 \mathrm{~Hz}$ Problem}

One of the major problems is the $5 \mathrm{~Hz}$ ripple. This ripple can be reduced perhaps by adding 60 and $120 \mathrm{~Hz}$ ripple damping filters. These filters, according to spice simulations will damped the $5 \mathrm{~Hz}$ bump by approximately $7 \mathrm{~dB}$ (refer to page 144 in the logbook).

144

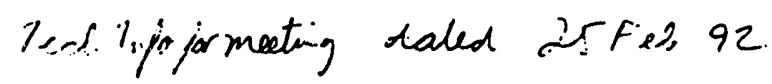
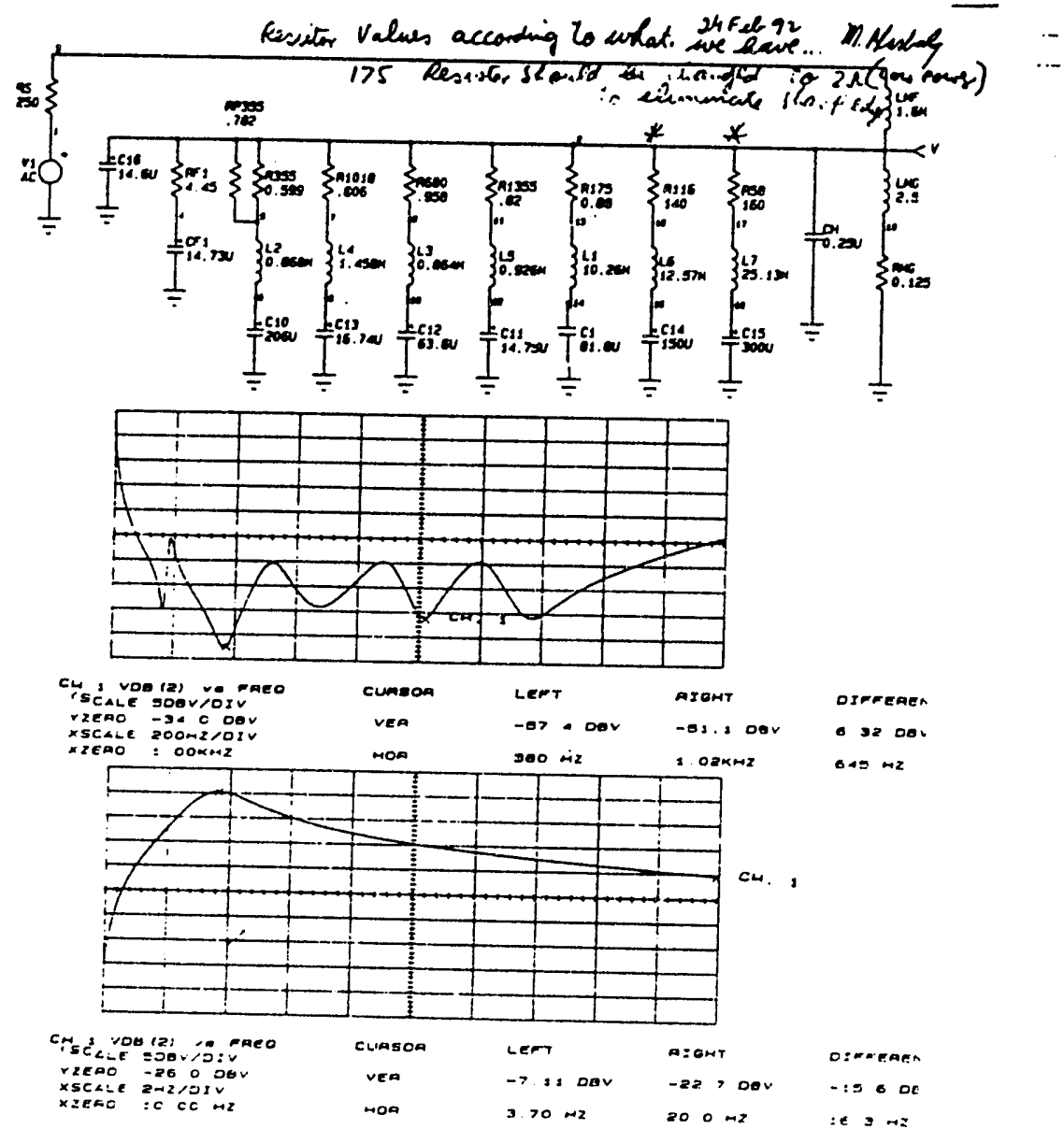

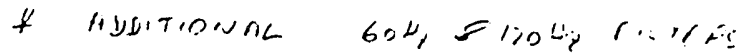




\subsection{Sharp Transient Response}

This problem can be "treated" by damping the filters. Suggested is to find the filter where value changes of serial damping resistors are the most essential without "paying too much" in attenuation of the spuriouses (motor generator harmonics magnitude).

\subsection{Mutual Induction}

Since a new construction in the pit took place, the mutual inductance is reduced to minimum. Spurious measurements should be taken in the $0-2 \mathrm{Khz}$ band and comparing these results to the old filter pit configuration (before May 92).

A spill histogram should also be taken comparing to undamped spill histograms in the past. 


\subsection{Damping Filter}

Suggested is to take data of spills (histograms) for the new damping filters set configuration. (ref. \#7.3)

\subsection{Ripple Reduction System}

Suggested is to analyze by simulation the RR system in the 0 to $10 \mathrm{KHz}$ frequency band, concentrating at the $5 \mathrm{~Hz}$ region. This, in the original configuration and the damped configuration. 

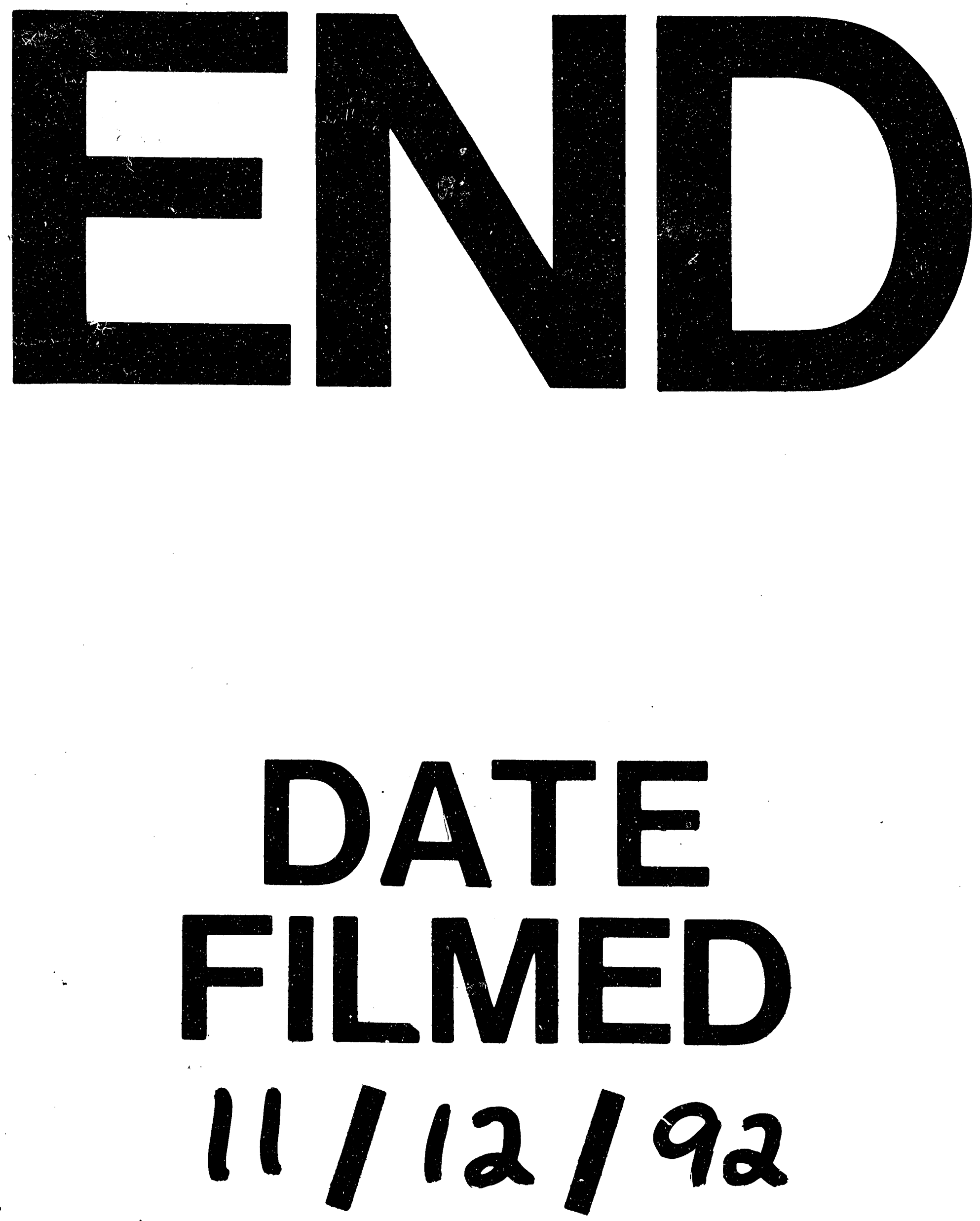

1 
